\title{
A New Hybrid Concept, Combining Lectures and Case-Seminars, Resulted in Superior Ratings from Both Undergraduate Medical Students and Teachers
}

\author{
Magnus Sundbom (1) \\ Per Hellstrom ${ }^{2}$ \\ Wilhelm Graf' \\ 'Department of Surgical Sciences, \\ Uppsala University, Uppsala, Sweden; \\ ${ }^{2}$ Department of Medical Sciences, \\ Uppsala University, Uppsala, Sweden
}

\begin{abstract}
Background: Due to declining student ratings, a new teaching method was applied to a course in gastrointestinal diseases for undergraduate medical students. Problem-based learning was replaced with our new concept, consisting of a theory week with traditional lectures and case seminars.
\end{abstract}

Methods: In this retrospective study, we compared student-ratings from the problem-based learning era to a new hybrid concept. The students evaluated the concepts by rating $(1-6,6=$ best) nine different subject areas. Additional free text comments were possible. Teachers working with both concepts did likewise. Statistical differences between the two periods were studied by Mann Whitney $U$-test.

Results: The study group consisted 621 students ( $57 \%$ females, total response rate of $52 \%$ ). Scores for lectures (4.9 vs.3.8) and teaching stimulation and feedback (4.6 vs 3.6, and 3.7 vs 3.4 , respectively), and to what extent the contents reflected learning goals ( 5.2 vs $4.3, \mathrm{p}<0.05$ for all) were instantly improved, which also prevailed in the following semesters. At the end of the study period, a significant improvement in case seminars (4.8 vs 4.3 ) and practical training ( 4.9 vs $3.8, \mathrm{p}<0.05$ for both) was seen. Free text answers revealed that the students felt more prepared for their clinical rotation. Teachers rated the new hybrid concept higher (4.7 vs $3.5, \mathrm{p}<0.05)$ and especially praised the new lectures.

Conclusion: The new learning concept resulted in both improved student-ratings and more satisfied teachers. We believe that the hybrid concept, combining lectures and case-seminars, facilitated learning and improved the learning climate. The subsequent uninterrupted practical training also received improved scores.

Keywords: lectures, undergraduate, medical student, curriculum, case-based learning, problem-based learning

\section{Background}

As our student-ratings in teaching gastrointestinal diseases for undergraduate medical students were declining, we needed to revise our learning concept. Over the years we used classroom lectures and book-based teaching, with repetition and examinations for reinforcement as well as newer teaching methods such as problem-based learning and some case-based seminars. ${ }^{1,2}$ Already in 1989, Walton and Matthews reported on the essentials of problem-based learning from a symposium at the World Federation of Medical Education, with the ambition to inform teachers in undergraduate, postgraduate and continuing medical education of this new form of education. The concept was considered to be a very valuable educational approach by the World Health
Correspondence: Magnus Sundbom Department of Surgical Sciences, Entrance 78, University Hospital, Uppsala, SE-75I 83, Sweden

Email magnus.sundbom@surgsci.uu.se 
Organisation (WHO). ${ }^{3}$ A decade later, Chang et al reported that problem-based learning improved student motivation and enjoyment, however, there was no convincing evidence of improved learning. The authors concluded that an intelligent combination of both traditional and problem-based learning would likely provide the most effective training for undergraduate surgical students. ${ }^{4}$ Based on the large interest in problem-based learning at that time, the concept was also introduced by us, mainly to trigger our students to be more active by presenting a clinical problem to solve. However, at our department, and when scrutinizing available systematic reviews and meta-analyses, the new teaching method failed to demonstrate superiority in undergraduate medical education. ${ }^{4-7}$ In 2016, we therefore launched a new hybrid concept based on a combination of classical lectures and case-seminars.

\section{The New Concept}

The new concept consists of one initial week of theoretical education followed by three weeks of uninterrupted practical training at our wards, specialised in gastroenterology and abdominal surgery. The theoretical week was based on disease-focused lectures in the morning and followed by case-studies in the afternoon (Figure 1). In establishing the new concept, all lectures were rewritten by one dedicated teacher and approved by a separate course leader. Lectures were grouped according to type of disease, eg, inflammatory bowel diseases, benign gastrointestinal conditions, abdominal pain and malignant diseases, and the different topics were then presented by their increasing complexity (from pharmacological treatment to elective, emergency, and malignant surgery).

The presented case-studies during the subsequent afternoon focused on topics from the theoretical lectures, thereby challenging students to use newly acquired knowledge to solve clinical problems. On the last day of the week, 12 different clinical cases, representing the most important diseases and conditions of the course, were assigned to the students in pairs, ie, one case per two students. These clinical cases, including their solution and important take-home messages, were to be presented by the students in the morning of the last day of the fourweek course. During that afternoon, a knowledge-based "clicker test" using a digital student response system was conducted.

The aim of the present study was to evaluate the introduction of the new hybrid learning concept in teaching gastrointestinal diseases for undergraduate medical students at our university hospital.

\begin{tabular}{|c|c|c|c|c|c|}
\hline & Monday & Tuesday & Wednesday & Thursday & Friday \\
\hline $08.00-08.45$ & $\begin{array}{l}\text { Introduction } \\
\text { Course leaders }\end{array}$ & Bariatric surgery & Proctology & Colorectal cancer & Liver diseases \\
\hline $09.00-09.45$ & $\begin{array}{l}\text { Medical } \\
\text { gastroenterology }\end{array}$ & $\begin{array}{l}\text { Benign } \\
\text { gastroesophageal } \\
\text { surgery }\end{array}$ & $\begin{array}{l}\text { Appendicitis, } \\
\text { diverticulitis }\end{array}$ & $\begin{array}{l}\text { Gastroesophageal } \\
\text { cancer }\end{array}$ & $\begin{array}{l}\text { Special cases in } \\
\text { gastroenterology }\end{array}$ \\
\hline $10.15-11.00$ & $\begin{array}{l}\text { Inflammatory bowel } \\
\text { diseases }\end{array}$ & Pancreatitis & $\begin{array}{l}\text { Bowel obstruction } \\
\text { and ischemia }\end{array}$ & Treatment of jaundice & Surgical complications \\
\hline $11.15-12.00$ & $\begin{array}{l}\text { Cont., including } \\
\text { surgical aspects }\end{array}$ & Gl-bleeding & Ostomies & Pancreatic cancer & $\begin{array}{l}\text { Rounds, including fluid } \\
\text { therapy }\end{array}$ \\
\hline & Lunch & Lunch & Lunch & Lunch & Lunch \\
\hline $13.00-13.45$ & $\begin{array}{l}\text { Case } 1 \\
\text { Inflammatory bowel }\end{array}$ & $\begin{array}{l}\text { Case } 2 \\
\text { Gl-bleedings }\end{array}$ & $\begin{array}{l}\text { Case } 3 \\
\text { Abdominal pain }\end{array}$ & $\begin{array}{l}\text { Case } 4 \\
\text { Investigation of } \\
\text { malignancies }\end{array}$ & $\begin{array}{l}\text { Clinical cases } \\
\text { Introduction and } \\
\text { distribution }\end{array}$ \\
\hline $14.00-14.45$ & $\begin{array}{l}\text { Case 1, discussion } \\
\text { and summary }\end{array}$ & $\begin{array}{l}\text { Case 2, discussion } \\
\text { and summary }\end{array}$ & $\begin{array}{l}\text { Case } 3 \text {, discussion } \\
\text { and summary }\end{array}$ & $\begin{array}{l}\text { Case } 4 \text {, discussion } \\
\text { and summary }\end{array}$ & Clinical cases, start-up \\
\hline
\end{tabular}

Figure I Schedule for the first week, the theoretical week, in the new concept for teaching gastrointestinal diseases to medical students. 


\section{Methods}

\section{Study Design}

Retrospective study by using aggregated student evaluations, provided by the Medical Study Council at the Undergraduate Medical Program at Uppsala University, from the last 13 semesters ( 7 before and 5 after the introduction of the new concept). Teachers having worked with both concepts were asked to compare their experiences in a short questionnaire.

\section{Participants}

The study group consisted of undergraduate medical students from a university hospital in Sweden and their teachers.

\section{Evaluation}

At the conclusion of the semester, students had been asked to rate the course in nine different learning areas: lectures, problem-based learning/case seminars, group seminars, practical training, agreement with learning goals, possibility to reach learning goals, teacher commitment, feedback, and opportunity to participate in learning activities. Each learning area was rated on a six-point scale ( 6 being the best) and additional comments could be made in free text fields. The students could also give additional comments in free-text fields. Unfortunately, we did not have access to the specific results from our course in gastrointestinal diseases as only the total score in the final exam was registered. Teachers were asked to compare lectures, cases, their own commitment, feedback from students and student activity between the new and former concept on a threegrade Likert scale (new better, no difference, former better) as well as their overall satisfaction with the two different courses (1-6, 6 being the best).

\section{Data Analysis}

Average scores were calculated for each area and semester. The first, (Spring 2016, $\mathrm{n}=52$ ), and last, semester (Spring 2018, $\mathrm{n}=45$ ) of the new concept were compared with the last semester of the former education (Fall 2015, n=58). Teacher-rated satisfaction was compared between the two concepts. Statistical differences were studied by Mann Whitney $U$-test. Descriptive statistics were used for the 4 questions concerning practical training.

\section{Ethical Approval}

As the manuscript only reports on aggregated data, collected from anonymous individuals at free will, no ethical approval is needed according to Swedish law.

\section{Results}

\section{Participants}

In total, 621 undergraduate medical students (57\% females) answered the questionnaire. The overall response rate was $52 \%$, ranging from 33 to $79 \%$ during the 13 semesters. Eleven out of 15 teachers $(73.3 \%)$ working within both concepts answered the questionnaire. To ensure anonymity, no other information concerning the participants, eg age, is available.

\section{Improved Student Scores}

The introduction of the new teaching concept showed instant improvement in scores for lectures, education mirroring the learning goals, and teacher-stimulation and feedback. Table 1. As demonstrated in Figures 2 and 3,

Table I Comparison of Student-Ratings from the Old Form of Education (Fall 2015), the New Concept (Started in Spring 20I6) and the Last Semester (Spring 2018). Scale of I-6, with 6 as the Best, for the Studied Nine Subgroups

\begin{tabular}{|l|c|c|c|c|c|}
\hline & $\begin{array}{c}\text { Old Form } \\
(\mathbf{n = 5 8 )}\end{array}$ & $\begin{array}{c}\text { New Concept } \\
(\mathbf{n = 5 2 )}\end{array}$ & $\begin{array}{c}\text { p-value Old vs } \\
\text { New }\end{array}$ & $\begin{array}{c}\text { Last Semester } \\
(\mathbf{n = 4 5 )}\end{array}$ & $\begin{array}{c}\text { p-value Old vs } \\
\text { Last }\end{array}$ \\
\hline Lectures & 3.8 & 4.9 & $<0.001$ & 5.1 & $<0.001$ \\
PBL/Case-seminars & 4.2 & 4.8 & 0.435 & 4.8 & 0.015 \\
Group seminars & 4.3 & 4.1 & 0.298 & 5.0 & 0.110 \\
Practical training & 3.8 & 4.5 & 0.222 & 4.9 & 0.011 \\
Mirrors goals & 4.3 & 5.2 & 0.002 & 5.0 & 0.024 \\
Reach goals & 4.7 & 4.9 & 0.764 & 4.9 & 0.803 \\
Teacher commitment & 3.6 & 4.6 & 0.004 & 4.8 & $<0.001$ \\
Feedback & 3.4 & 3.7 & 0.035 & 3.9 & 0.043 \\
Opportunity to participate & 4.5 & 4.7 & 0.535 & 4.9 & 0.230 \\
\hline
\end{tabular}




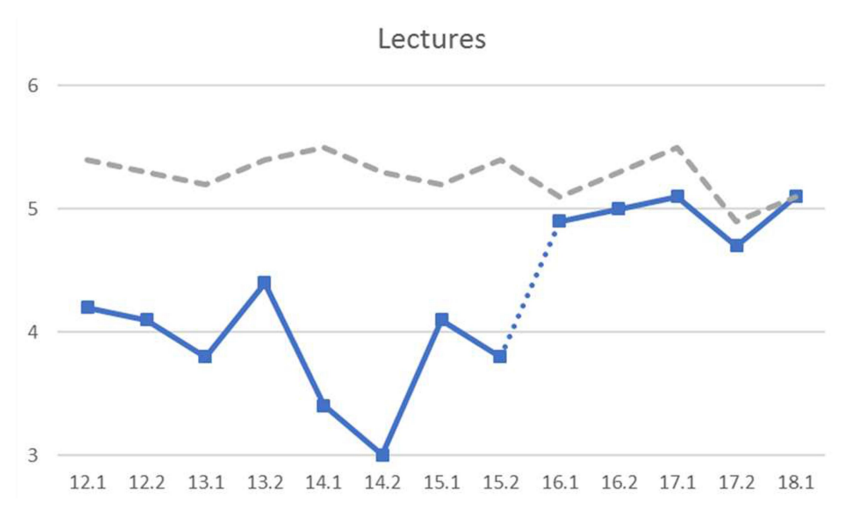

Group seminars

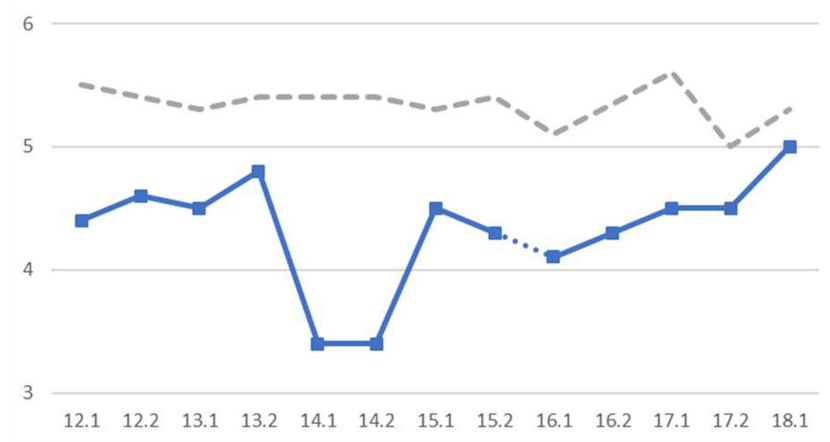

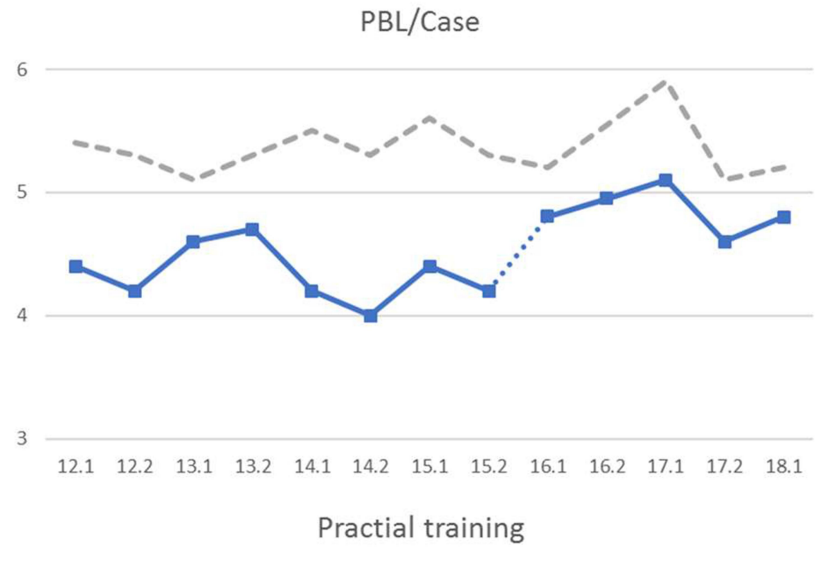

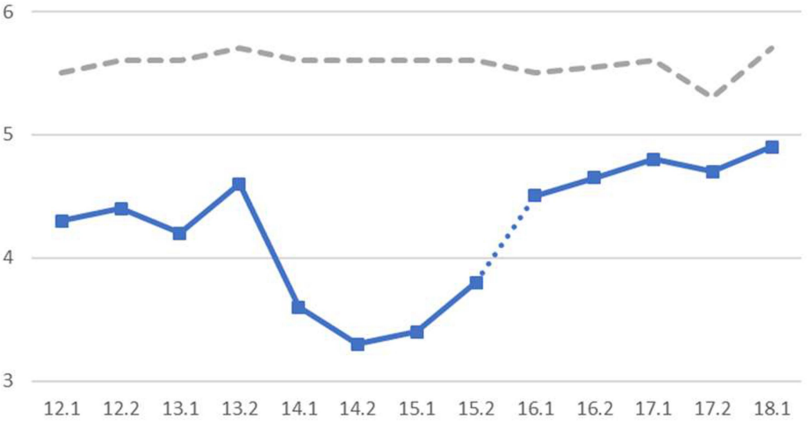

Figure 2 Scores ( $1-6$, with 6 the best) from $62 \mathrm{I}$ individual students ( $57 \%$ females) on the quality of the given lectures, group seminars, problem-based learning/case-studies and practical training during 2012 to 2018 . Note the introduction of the new teaching concept in the spring semester of 2016 (16:I, after the dotted line). The broken line represents the results from a continuously high-ranked department in our semester.

the improved scores prevailed for the following semesters. At the end of the study period (Spring 2018), a significant improvement in case seminars and practical training was seen compared to the former concept. Notably, our scores, especially for lectures and learning goals, are approaching those of Anaesthesiology, a discipline which is taught in the same semester as ours and continuously ranks in the top three of all clinical courses in student-rating.

\section{Free Text Comments and the Clicker-Based Test}

It is also worth noting that the free text comments indicated improvement. Up until 2015, students continuously complained of lack of theoretical education, especially those having their practical training at other hospitals in our region. After introducing the new concept, 21 of 56 students spontaneously used the free text field to comment positively on the new theoretical week. The clicker-based test was popular among the students, with comments such as it "provided a good discussion", "allowed me to try my knowledge on all questions" and "it was not as scary as an oral examination".

\section{Teacher-Rated Satisfaction}

As demonstrated in Figure 4, teachers considered lectures, cases, own commitment as well as feedback from students and student activity to be better for the new concept. The largest difference was seen in lectures, also commented in the free field by "less extra work before having a lecture", "identical lectures during all four rounds of the course makes the final exam more fair for the students", and "feels more professional, just like the ATLS course". In addition, the initial theoretical week was praised by comments like "students are more prepared at the wards" and "the clinical rotation has become undisturbed". Finally, the possibility to repeat and discuss important facts during the students' presentation of their clinical cases on the last day of the course was mentioned. The teachers' overall satisfaction with the course increased from 3.5 to $4.7, \mathrm{p}<0.05$.

\section{Discussion}

The new hybrid teaching concept instantly improved the ratings of lectures by students, the correlation between teaching and learning goals, and teacher stimulation and feedback. In addition, these results prevailed in subsequent 


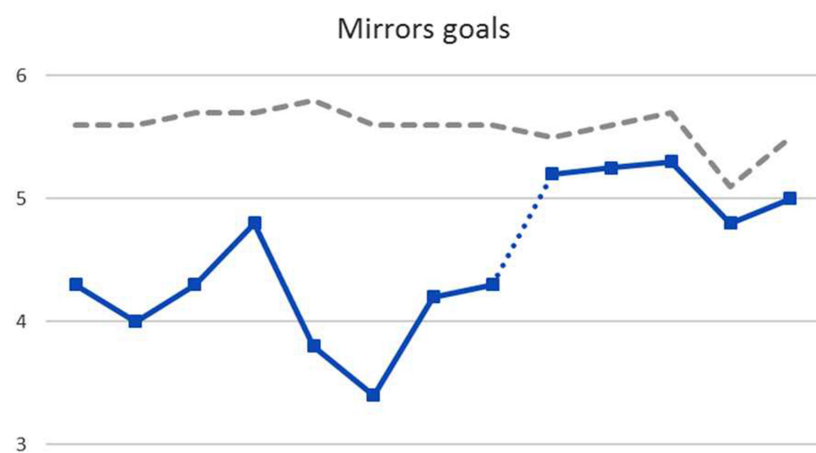

$\begin{array}{lllllllllllll}12.1 & 12.2 & 13.1 & 13.2 & 14.1 & 14.2 & 15.1 & 15.2 & 16.1 & 16.2 & 17.1 & 17.2 & 18.1\end{array}$

Teaching stimualtion

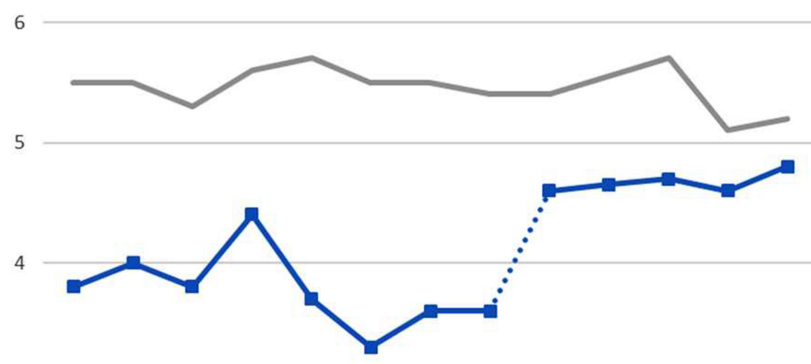

3

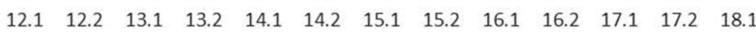

Opportunity to participate

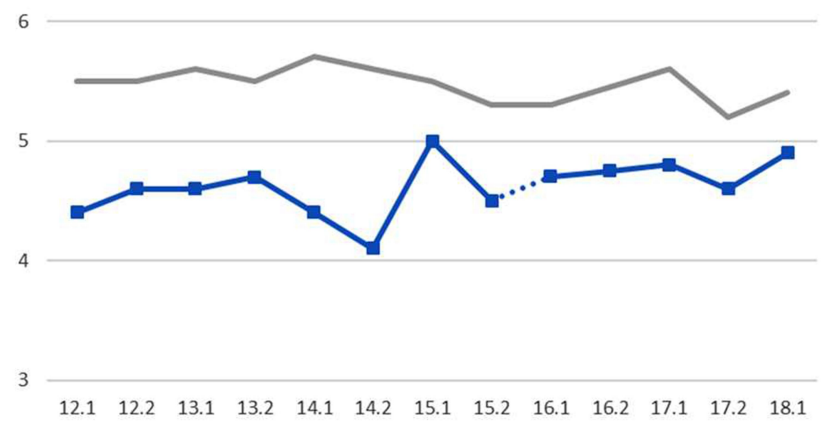

Reach goals

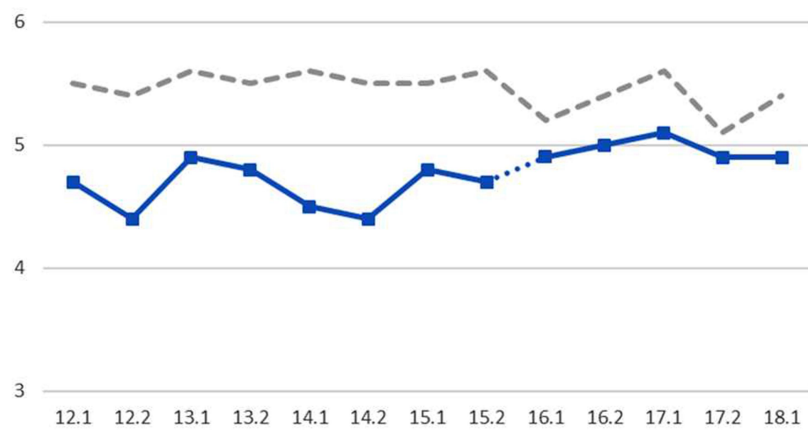

Feedback
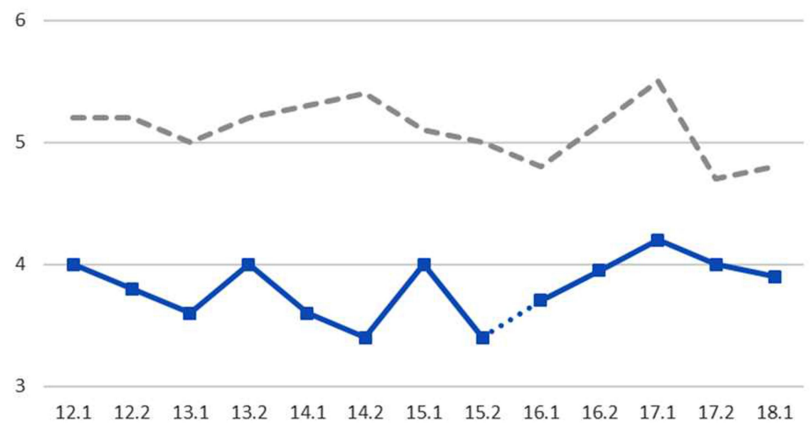

Figure 3 Student-rating $(\mathrm{I}-6)$ of to what extent the given education mirrored the learning goals and their possibility to reach them, and teaching stimulation, feedback and opportunity to participate. Introduction of the new teaching concept after the dotted line, while the broken represents the results from a high-ranked department in our semester.

semesters. At the end of the study period, a significant improvement in case seminars and practical training was also seen. In the free text answers, many students praised the theoretical week, expressing it to be well-adapted to their forthcoming clinical rotation.

We are pleased with the improved scores and believe that the parallel use of a teaching method well-known to teachers (traditional lectures) and adding case seminars (similar to the problem-based learning method), which is familiar to students from former semesters, eased the introduction of the new hybrid concept. Our experience is in line with the hybrid learning curriculum of Lee at al, in which 93 students thought lectures helped in selecting study topics and learning for the tutorial case. ${ }^{8}$ This was also true for 40 first-year postgraduate students in oncology, when randomised into a case-based learning group and compared to controls having only traditional lecture-based teaching. ${ }^{9}$ Moreover, Dubey et al found a highly significant improvement in the students' higher level of cognition when adding case-based learning to 81 undergraduate medical students. ${ }^{10}$

When choosing between teaching systems, the students' maturity is of importance. In a cross-sectional study of 


\section{LECTURES}

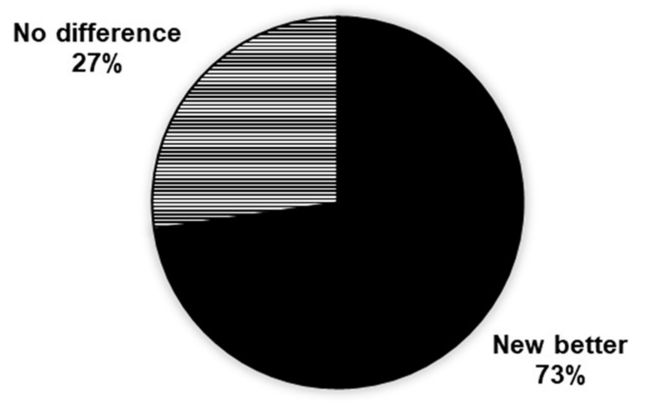

OWN COMITTMENT
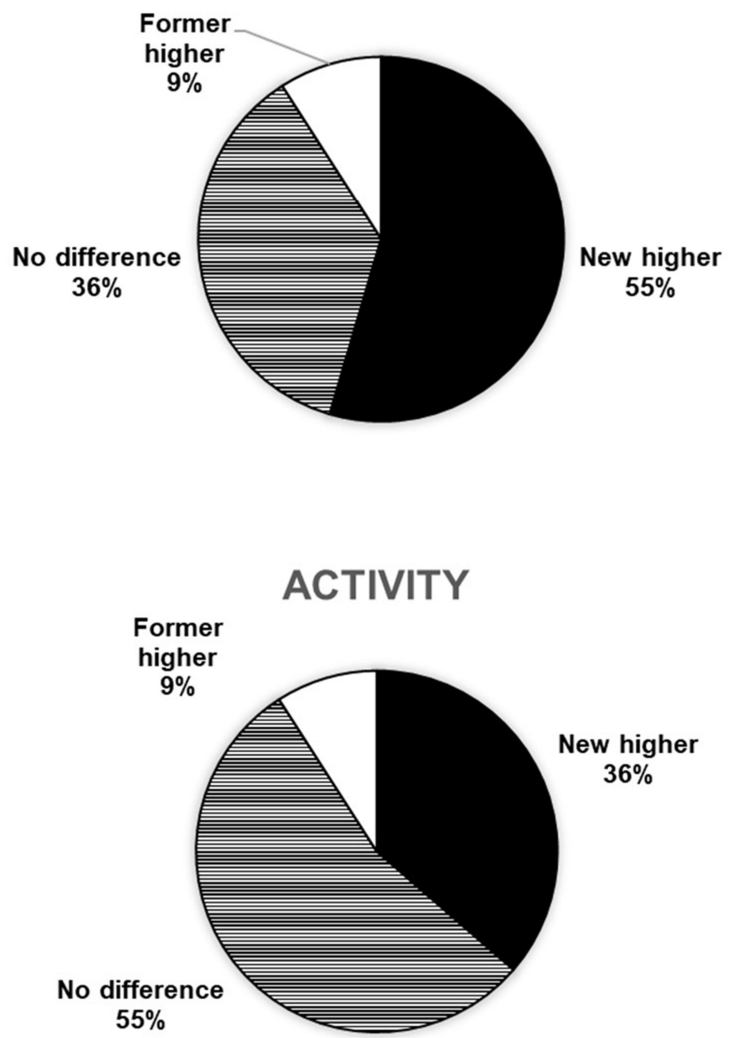

CASES

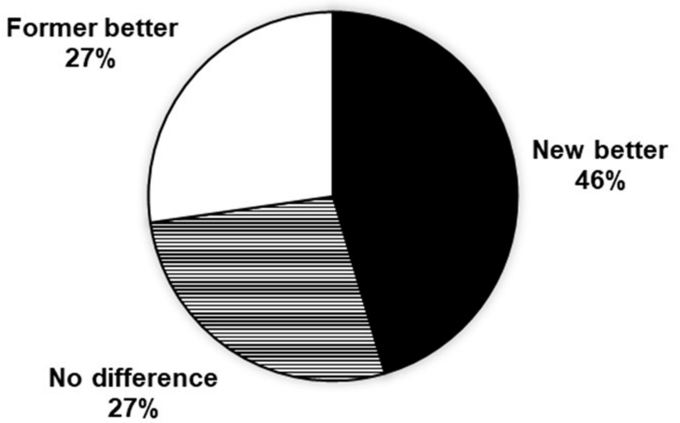

FEEDBACK

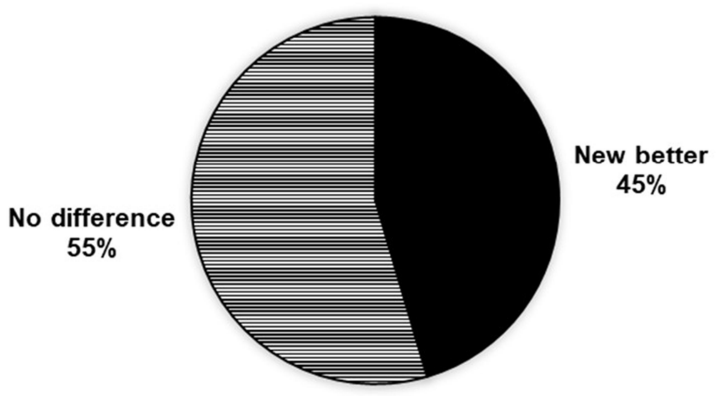

Figure 4 Teacher-scored comparison of lectures, cases, their own commitment, feedback from students and student activity between the new and former concept on a three-grade Likert scale (new better, no difference, former better). Note the overall improvements, especially in lectures.

students' evaluation of teaching methods, clinically oriented methods such as case-based learning were preferred by second-year medical students, while lecturebased instructions were more popular among first-year students. ${ }^{11}$ A hybrid course combining case-based and lecture-based teaching has also been designed in other disciplines, such as nanobioscience for senior undergraduate students, as the combination of the two different approaches to learning were considered valuable and provided the opportunity to develop complementary skills. ${ }^{12}$ A complete switch to self-directed learning was found not to be superior by 130 Norwegian medical students, ${ }^{13}$ nor at another Swedish medical university in Stockholm; rather students reported the introduction to be unsatisfactory due to misalignment between the general concept and the reigning teaching and learning principles. ${ }^{14}$ 
It is important to activate students and involve them in their own learning process, which otherwise can be perceived as passive. The new case-seminars in the afternoons of the theoretical week were meant to engage the students by allowing them to reflect on various problems in small groups and then discuss the case with the whole class. The use of concept maps and case-based learning has been proven useful in integrating previous knowledge into new clinical information for case analysis and to elicit diagnosis. ${ }^{15}$ The studied students also reported an increase in content-related knowledge. In an American study of first-year preclinical medical students, a significant achievement in critical thinking and teamwork among students was seen when using a case-based curriculum. Furthermore, student groups integrated basic science and clinical concepts significantly better. ${ }^{16}$ Moreover, in a single-centre randomised controlled trial with 106 German medical students, participants taking part in live clinical case discussions (CCD) scored the best results, followed by video-CCD (watching recordings of live discussions) and a group working with printed cases (papercases). ${ }^{17}$ The authors stress that the subjective learning experience underlines the importance of learner (inter) activity in acquisition of clinical reasoning skills. Finally, 84 American medical students taking part in a case-based learning program (PEARLS) during the first and second years of medical school improved in four leadership traits (self-assured, persistent, determined, and outgoing) in both peer and facilitator-rated assessments. Six additional traits, out of 14 in total, significantly improved by measurement of facilitator-rated assessment. ${ }^{18}$

The correlation between the education in the new concept and the learning goals, unchanged during the study period, was rated high by the students. As not all teachers are aware of the learning goals when preparing their individual presentations, our central bank of approved lectures was critical to achieving this. This notion has been proved successful also in the more complex worldwide launch of ATLS, training in advanced trauma life support by the American College of Surgeons. ${ }^{19}$ Furthermore, the fixed lectures hindered teachers from compiling their own presentations just a couple of days before delivering the lecture. This also addressed a former complaint from students that posted presentations were inconsistent with the actual lecture.

The improved scores on feedback and teacher commitment occurred when our teachers were more involved, for example by taking part in rewriting the course material and allowed to teach one of their own favourite subjects. This is in line with Van den Engbers et al who, using the Work-related Basic Need Satisfaction scale ${ }^{20}$ in 767 medical teachers at a university hospital, found autonomy, competence, and relatedness to be most important when measuring the satisfaction towards teaching. ${ }^{21}$

Although our students earlier experience of problembased learning in former semesters probably facilitated the introduction, it took a couple of semesters to optimize the case seminars. The content had to match, and complement, the morning lecture. Moreover, case seminars can be demanding for the teacher, who must capture and frame questionable answers. It is also difficult to keep the case at the centre of the discussion and to make sure that every student is involved. It is worth noting that related pathologies and the process of differential diagnosis are as important for the students to master as the pathology specified in each case studied. For example, eg, in evaluating liver values, the specific patterns reflecting all types of typical diagnoses are important learning objectives.

By routinely using clickers at the last day of the course, we could easily get an idea of the students' performance and invite them to discuss their answer on 15 multiplechoice questions, reflecting the most important knowledge in the course. We believe that the clicker test resulted in greater activity among the students than the previously used written test. Furthermore, the responses are automatically saved and can therefore be used for future evaluations, as used in the present study and at faculty meetings.

In accordance with the free text answers, we believe that the new concept better prepares the students for their clinical rotation. In a systematic review of 20 unique studies, positive experiences during the clinical rotation, especially in the operating theatre, were associated with an increased interest in surgical careers. ${ }^{22}$ Two American studies identified mentorship and personal factors, ${ }^{23}$ and operative exposure and interaction with residents and faculty, ${ }^{24}$ respectively, to be the major determinants for medical students to pursue surgery. Thus, residents are crucial in many of these areas as mediators of unscheduled teaching.

\section{Limitations}

The response rate was not optimal (58\%) and we cannot present which types of students (dissatisfied, pleased, motivated) responded. The questionnaire was, however, distributed by a student organisation and answered anonymously, directly after the final exam on the last day of the 
semester. Although the students of the Spring term of 2016 were not informed that the teaching concept had been changed, we cannot exclude that they suspected this after talking to former students. Moreover, we have been unable to correlate the present student ratings to knowledge acquisition as we lacked the specific results from our course in the final exams and the clicker-test was introduced at the start of the new concept. Furthermore, instead of relying on scores and information in the free text fields, we could have performed qualitative semi-structured interviews with both students and faculty to support our findings. However, the marked and persistent improvement in student-ratings and simultaneous increase teacher satisfaction suggest a strong correlation to the new hybrid concept. Finally, we believe that the larger group of teachers of various expertise, rather than a small group of dedicated individuals, strengthens the results and adds general applicability.

We are pleased with the improved scores but yet aim to improve our results, firstly by studying our colleagues in Anaesthesiology more in detail. Another developing learning strategy in our clinical setting is interprofessional learning, which is popular among undergraduate healthcare professionals. $^{25}$ Additionally, advanced teaching methods, such as computer simulation, have recently proven to be effective and essential adjuncts in bridging gaps between classroom medicine and clinical practice. ${ }^{26}$ Most important, adopting already well-functioning concepts is a good path to success as the implementation of a new teaching policy in a university hospital lies at the departmental level to a large degree. ${ }^{27}$

\section{Conclusion}

The new teaching concept with an initial theoretical week based on a mix of classical lectures and case seminars instantly improved the student-scores for lectures, learning goals and student-teacher interaction, a result that prevailed for the following semesters. In accordance with the free text answers, we believe that the new concept better prepares the students for their clinical rotation. At the end of the study period, a significant improvement in case seminars and practical training was seen. Satisfaction with the new concept among teachers was also increased and believe that the thorough follow up of the new concept at the biannual teacher meetings was key to the achieved and sustained good results. We hope that our work with curriculum development through introduction of new learning activities can inspire others, especially those engaged in undergraduate medical education.

\section{Acknowledgments}

The authors would like to acknowledge the continuous work of the Medical Study Council at the Undergraduate Medical Program, Uppsala University in collecting student evaluations from all courses.

\section{Disclosure}

The authors report no conflicts of interest in this work.

\section{References}

1. Williams B. Case based learning-a review of the literature: is there scope for this educational paradigm in prehospital education? Emerg Med J. 2005;22(8):577-581. doi:10.1136/emj.2004.022707

2. McLean SF. Case-based learning and its application in medical and health-care fields: a review of worldwide literature. J Med Educ Curric Dev. 2016;3:JMECD.S20377. doi:10.4137/JMECD.S20377

3. Walton HJ, Matthews MB. Essentials of problem-based learning. Med Educ. 1989;23(6):542-558. doi:10.1111/j.1365-2923.1989.tb01581.x

4. Chang G, Cook D, Maguire T, Skakun E, Yakimets WW, Warnock GL. Problem-based learning: its role in undergraduate surgical education. Can J Surg. 1995;38(1):13-21.

5. Albanese MA, Mitchell S. Problem-based learning: a review of literature on its outcomes and implementation issues. Acad Med. 1993;68(1):52-81. doi:10.1097/00001888-199301000-00012

6. Norman GR, Schmidt HG. The psychological basis of problem-based learning: a review of the evidence. Acad Med. 1992;67(9):557-565. doi:10.1097/00001888-199209000-00002

7. Nandi PL, Chan JN, Chan CP, Chan P, Chan LP. Undergraduate medical education: comparison of problem-based learning and conventional teaching. Hong Kong Med J. 2000;6(3):301-306.

8. Lee YM, Mann KV, Frank BW. What drives students' self-directed learning in a hybrid PBL curriculum. Adv Health Sci Educ Theory Pract. 2010;15(3):425-437. doi:10.1007/s10459-009-9210-2

9. Bi M, Zhao Z, Yang J, Wang Y. Comparison of case-based learning and traditional method in teaching postgraduate students of medical oncology. Med Teach. 2019;1-5.

10. Dubey S, Dubey AK. Promotion of higher order of cognition in undergraduate medical students using case-based approach. $J$ Educ Health Promot. 2017;6:75. doi:10.4103/jehp.jehp_39_17

11. Zinski A, Blackwell K, Belue FM, Brooks WS. Is lecture dead? A preliminary study of medical students' evaluation of teaching methods in the preclinical curriculum. Int $J$ Med Educ. 2017;8:326-333. doi:10.5116/ijme.59b9.5f40

12. Kazeruni NMB, Laboy A, Hess H. Designing a hybrid engineering course combining case-based and lecture-based teaching. Conf Proc IEEE Eng Med Biol Soc. 2018;2018:1636-1639.

13. Lycke KH, Grottum P, Stromso HI. Student learning strategies, mental models and learning outcomes in problem-based and traditional curricula in medicine. Med Teach. 2006;28(8):717-722. doi:10.1080/ 01421590601105645

14. Nordquist J, Sundberg K, Johansson L, Sandelin K, Nordenstrom J. Case-based learning in surgery: lessons learned. World J Surg. 2012;36(5):945-955. doi:10.1007/s00268-011-1396-9

15. Penuela-Epalza M, De la Hoz K. Incorporation and evaluation of serial concept maps for vertical integration and clinical reasoning in case-based learning tutorials: perspectives of students beginning clinical medicine. Med Teach. 2019;41(4):433-440. doi:10.1080/ 0142159X.2018.1487046

16. Slieman TA, Camarata T. Case-based group learning using concept maps to achieve multiple educational objectives and behavioral outcomes. J Med Educ Curric Dev. 2019;6:2382120519872510. doi:10.1177/2382120519872510 
17. Weidenbusch M, Lenzer B, Sailer M, et al. Can clinical case discussions foster clinical reasoning skills in undergraduate medical education? A randomised controlled trial. BMJ Open. 2019;9(9):e025973. doi:10.1136/bmjopen-2018-025973

18. Ginzburg SB, Schwartz J, Gerber R, et al. Assessment of medical students' leadership traits in a problem/case-based learning program. Med Educ Online. 2018;23(1):1542923. doi:10.1080/10872981.20 18.1542923

19. Mohammad A, Branicki F, Abu-Zidan FM. Educational and clinical impact of Advanced Trauma Life Support (ATLS) courses: a systematic review. World J Surg. 2014;38(2):322-329. doi:10.1007/s00268-013-2294-0

20. Van den Broeck A, Vansteenkiste M, De Witte H, Soenens B, Lens W. Capturing autonomy, competence and relatedness at work: construction and initial validation of the work-related basic need satisfaction scale. J Occup Organ Psychol. 2010;4 (83):981-1002.

21. Engbers R, Fluit CR, Bolhuis S, Sluiter R, Stuyt PM, Laan RF. Relations between policy for medical teaching and basic need satisfaction in teaching. Adv Health Sci Educ Theory Pract. 2015;20 (4):969-980. doi:10.1007/s10459-014-9575-8
22. Marshall DC, Salciccioli JD, Walton SJ, Pitkin J, Shalhoub J, Malietzis G. Medical student experience in surgery influences their career choices: a systematic review of the literature. J Surg Educ. 2015;72(3):438-445. doi:10.1016/j.jsurg.2014.10.018

23. Schmidt LE, Cooper CA, Guo WA. Factors influencing US medical students' decision to pursue surgery. J Surg Res. 2016;203(1):64-74. doi:10.1016/j.jss.2016.03.054

24. O'Herrin JK, Lewis BJ, Rikkers LF, Chen H. Why do students choose careers in surgery? J Surg Res. 2004;119(2):124-129. doi:10.1016/j.jss.2004.03.009

25. Nasir J, Goldie J, Little A, Banerjee D, Reeves S. Case-based interprofessional learning for undergraduate healthcare professionals in the clinical setting. $J$ Interprof Care. 2017;31(1):125-128. doi:10.1080/13561820.2016.1233395

26. Giblett N, Rathore R, Carruthers D. Simulating the surgical patient pathway for undergraduates. J Surg Educ. 2017;74(2):271-276. doi:10.1016/j.jsurg.2016.10.003

27. Engbers R, Fluit C, Bolhuis S, de Visser M, Laan R. Implementing medical teaching policy in university hospitals. Adv Health Sci Educ Theory Pract. 2017;22(4):985-1009. doi:10.1007/s10459-016-9737-y

\section{Publish your work in this journal}

Advances in Medical Education and Practice is an international, peerreviewed, open access journal that aims to present and publish research on Medical Education covering medical, dental, nursing and allied health care professional education. The journal covers undergraduate education, postgraduate training and continuing medical education including emerging trends and innovative models linking education, research, and health care services. The manuscript management system is completely online and includes a very quick and fair peer-review system. Visit http://www.dovepress.com/testimonials.php to read real quotes from published authors. 